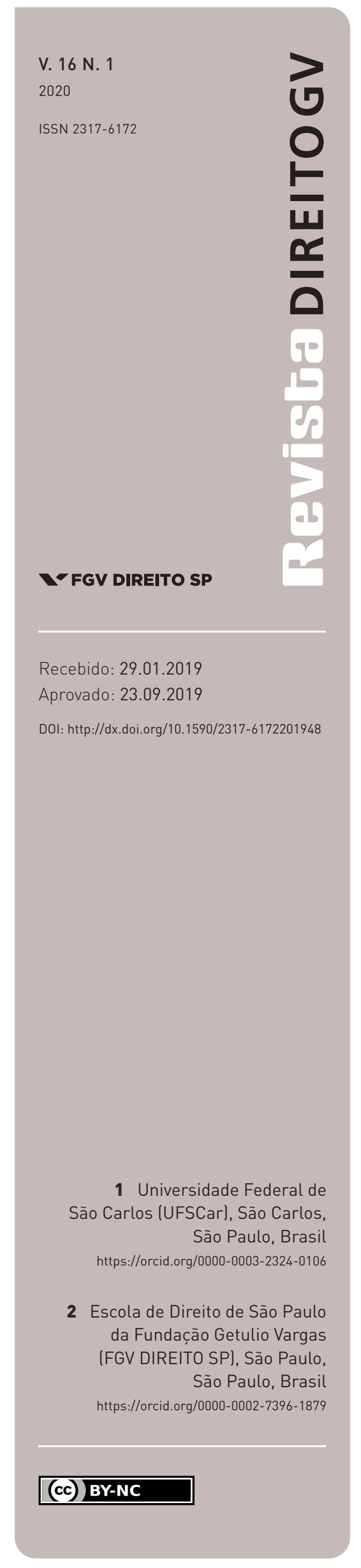

\title{
Os indicadores sobre o Judiciário brasileiro: limitações, desafios e o uso da tecnologia
}

THE INDICATORS ON THE BRAZILIAN JUDICIARY: LIMITATIONS, CHALLENGES AND THE USE OF TECHNOLOGY

\author{
Fabiana Luci de Oliveira ${ }^{1}$ e Luciana Gross Cunha²
}

\section{Resumo}

O objetivo deste artigo é avaliar a produção de dados sobre as atividades do Judiciário, verificando suas limitações em termos de confiabilidade e instrumentalidade. Dentro da grande área Direito e Tecnologia, o foco principal dos estudos tem sido o impacto da tecnologia nas profissões jurídicas e nos serviços prestados pelos operadores da Justiça. Este artigo joga luz sobre o uso da tecnologia na gestão das atividades jurisdicionais do Estado, mais especificamente no Poder Judiciário, a fim de propor aspectos a serem incorporados para a transformação das estatísticas judiciais em informações capazes de subsidiar políticas públicas que tenham como finalidade não apenas a gestão judicial, mas, sobretudo, o aperfeiçoamento da prestação jurisdicional.

\section{Palavras-chave}

Poder Judiciário; estatísticas judiciais; eficiência; tecnologia; administração da Justiça.

\section{Abstract}

The purpose of this article is to evaluate the production of data on the activities of the Brazilian Judiciary, checking its limitations in terms of reliability and instrumentality. Within the large area of Law and Technology, the main focus of studies has been the impact of technology on the legal professions and the services provided by its operators. This article sheds light on the use of technology in the management of the jurisdictional activities of the state, more specifically in the Judiciary, in order to propose aspects to be incorporated for the transformation of judicial statistics into information capable of subsidizing public policies that aim not only at judicial management, but above all the improvement of the judicial services.

\section{Keywords}

Brazilian Judicial Power; judicial statistics; efficiency; technology; administration of Justice. 


\section{INTRODUÇÃO}

Este artigo trata da produção de dados sobre as atividades do Poder Judiciário brasileiro como medida quantitativa de seu desempenho, verificando suas limitações em termos de confiabilidade e instrumentalidade. Para isso, apoia-se em pesquisa documental e bibliográfica, retomando o histórico da produção de estatísticas judiciais no país, detendo-se na evolução do relatório Justiça em Números, analisado à luz das recomendações dos principais organismos internacionais encarregados da avaliação da eficiência de sistemas de justiça, como o Banco Mundial, a Comissão Europeia pela Eficiência na Justiça (CEPEJ) e o International Consortium for Court Excellence (ICCE).

A tecnologia e seu uso são centrais não somente na produção e na circulação das informações sobre o funcionamento do Judiciário, como também em sua gestão administrativa. A produção de dados e estatísticas judiciais no Brasil tem longa tradição. Conforme documentam Sadek e Oliveira (2012), estatísticas judiciais são geradas desde o início da República. Algumas, inclusive, eram mais detalhadas do que as de que dispomos hoje, sobretudo com relação aos processos criminais, que traziam o perfil dos casos, por tipo, incluindo indicadores demográficos dos réus.

A partir da criação do Instituto Brasileiro de Geografia e Estatística (IBGE) na década de 1930, os anuários estatísticos passaram a trazer informações sobre a atuação da Justiça, com cobertura variável, destacando-se dados gerais sobre a criminalidade e a repressão, e a movimentação processual do Supremo Tribunal Federal (STF). Ao longo do tempo, contudo, essas informações foram escasseando e perdendo acuidade no grau de especificidade (SADEK e OLIVEIRA, 2012, p. 22-23).

Após a promulgação da Constituição de 1988, ficou a cargo do próprio Poder Judiciário sistematizar suas estatísticas, com a criação do Banco Nacional de Dados do Poder Judiciário (BNDPJ), administrado pelo STF. Esse banco reunia dados sobre: a quantidade de cargos de juiz (existentes e providos); concursos realizados e em andamento; número de processos ingressados e julgados; natureza das causas; número de comarcas, varas e juizados existentes; proporção de ações cíveis e criminais; o percentual de processos cuja parte fosse a Administração Pública; o tempo médio para o julgamento final dos processos em cada instância; entre outras informações (SADEK e OLIVEIRA, 2012, p. 26).

Com a aprovação da Emenda Constitucional (EC) n. 45, em 2004, conhecida por "Reforma do Judiciário", e a instalação do Conselho Nacional de Justiça (CNJ), em 2005, o Judiciário passou a ter um órgão centralizador das estatísticas judiciais, responsável por seu recebimento, seu processamento e sua publicação.

Esses dados integram o Sistema de Estatística do Poder Judiciário (SIESPJ), repositório oficial de dados da Justiça brasileira, criado pela Resolução n. 4, de 16 de agosto de 2005, e regulamentado pela Resolução n. 15, de 20 de abril de 2006, posteriormente substituída pela Resolução n. 76, de 15 de maio de 2009, orientando a coleta de dados e a publicação anual do relatório Justiça em Números. 
A produção de dados estatísticos confiáveis, que permitam a instituição de um planejamento estratégico e o monitoramento de ações voltadas à melhoria da prestação jurisdicional, faz parte de uma tendência global na administração pública, no sentido de adotar instrumentos capazes de monitorar o desempenho organizacional e orientar práticas voltadas à otimização da alocação de recursos e à melhoria dos serviços prestados. Essa tendência se iniciou no Poder Executivo, na década de 1980 (NOGUEIRA, 2010), e chegou ao Judiciário no final da década de 1990, em um movimento liderado pelo Banco Mundial, com a instituição dos Indicadores de Governança Mundial (AMARILES, 2016).

Os Indicadores de Governança Mundial, por sua vez, foram inspirados no documento conhecido como Consenso de Washington, publicado em 1998 (BURKI e PERRY, 1998) pelo Fundo Monetário Internacional (FMI), que definiu um conjunto de medidas político-institucionais a serem aplicadas em países não desenvolvidos, por meio de reformas do Estado, a fim de promover um maior desenvolvimento, atraindo, assim, financiamento internacional.

Com base nesse documento, não somente o Banco Mundial, mas diversas outras agências internacionais, como o Banco Interamericano de Desenvolvimento (IDB) e a Agência Norte- Americana para o Desenvolvimento Internacional (USAID), passaram a promover programas de financiamento para a reforma de instituições governamentais com o fim de atender às medidas indicadas pelo Consenso de Washington (DOMINGO e SIEDER, 2001). Nesse sentido, a implementação e o fortalecimento do rule of law, a fim de que o sistema de Justiça fosse independente e que garantisse segurança jurídica e previsibilidade de suas decisões, eram alguns dos princípios norteadores de tais medidas, e, no caso do Judiciário, levaram ao desenvolvimento de indicadores de monitoramento de suas atividades (CUNHA, 2008).

A criação, pelo Banco Mundial, de indicadores jurídicos transnacionais voltados à identificação de problemas e à orientação de projetos de reforma do Judiciário estava alinhada com o princípio do rule of law. O objetivo central desses indicadores era apoiar a política de desenvolvimento econômico, mensurando a eficiência judicial, com destaque para a rapidez (prazos processuais) e a previsibilidade das decisões judiciais. A eficiência foi a principal medida de desempenho judicial adotada, com a preocupação de verificar quão bem os recursos (financeiros, materiais e humanos) eram empregados na geração de resultados nos tribunais (decisões).

De acordo com Buscaglia e Dakolias (1999, p. 2): "Inefficiency causes delays, which raise litigant-related costs; higher costs in turn impede user access to the courts, and thereby damage faith in the legal system. Efficiency is therefore an important aspect of a judiciary's effectiveness". 1

Essa orientação para a mensuração de eficiência levou à necessidade de produção de dados e sua transformação em informações confiáveis para identificar problemas e alcançar soluções,

1 Em tradução livre: "A ineficiência causa atrasos, que aumentam os custos relacionados ao litigante; os custos mais altos, por sua vez, impedem o acesso dos usuários aos tribunais e, assim, prejudicam a fé no sistema legal. A eficiência é, portanto, um aspecto importante da eficácia do Judiciário”. 
sendo instrumento indispensável para concretizar mudanças e melhorias na prestação jurisdicional. Assim, argumenta-se que as estatísticas judiciais podem ter impacto benéfico para a accountability e a responsabilização judicial, contribuindo para melhorar a capacidade do Judiciário de fornecer respostas eficazes à sociedade e aos demais Poderes do Estado (ELENA, 2015).

A existência e a publicidade de dados são necessárias a fim de que: (i) o público possa conhecer quais são as atividades desenvolvidas pelo Judiciário; (ii) os órgãos de cúpula possam monitorar seu desempenho e planejar projetos futuros; (iii) os governos possam elaborar e promover políticas públicas de reforma e melhoria nessa área; (iv) os experts possam avaliar o funcionamento do sistema de Justiça como um todo (CUNHA, 2010).

Em perspectiva comparada, é possível indicar um conjunto de variáveis mínimas, em termos de accountability e responsividade, que o Poder Judiciário deve apresentar. Essas variáveis são pautadas principalmente por organismos internacionais, que estão envolvidos na avaliação da eficiência do sistema de Justiça, como o Banco Mundial e a CEPEJ. De maneira geral, esses organismos recomendam que o Judiciário produza informações sobre suas atividades, que essas informações sejam acessíveis, de qualidade, atualizadas e que possam ser comparadas com as de outros sistemas de informações, sejam eles nacionais ou internacionais.

Entre as informações que são consideradas importantes estão: (i) o número de processos iniciados por ano; (ii) o número de casos resolvidos por ano; (iii) o número de casos pendentes no final de cada ano; (iv) a taxa de atendimento à demanda (clearance rate); (v) a taxa de congestionamento; (vi) a média de duração dos casos; (vii) o número de juízes por cem mil habitantes. Esses dados devem estar organizados por área, por instância judicial e por jurisdição (DAKOLIAS, 1999, p. 7). Devem ser de fácil acesso, com apresentação e linguagem objetivas.

Os dados sobre as atividades do Judiciário devem, ainda, ser coletados, preferencialmente, a partir do sistema de andamento processual. O tamanho, o conteúdo e a idade do acervo de dados também são importantes, a fim de que cada um dos tribunais possa identificar o que não está sendo decidido. Além disso, os sistemas estatísticos construídos a partir dessas informações devem servir como mecanismos objetivos de avaliação da administração judiciária, na medida em que instrumentalizam: (i) os juízes, na administração de seus tribunais; (ii) os legisladores, na avaliação dos conflitos gerados a partir da elaboração de uma lei; (iii) os cidadãos e as organizações que utilizam o Judiciário, como forma de reduzir a incerteza jurídica (CUNHA, 2008).

A partir das orientações desses organismos internacionais, surgiu o ICCE (ICCE, 2018), que desenvolveu um arcabouço metodológico para a avaliação do desempenho judicial. O relatório traz a definição das medidas, seu propósito, a metodologia para obtenção e cálculo, definindo a lógica de mensuração como um processo e uma disciplina de gerenciamento.

Court performance measurement and management (PMM) is the discipline and the process of monitoring, analyzing, and using organizational performance data on a regular 
(ideally in real or near-real time) and continuous basis for the purposes of improvements in organizational efficiency and effectiveness, in transparency and accountability, and in public trust and confidence in the courts and the justice system. (ICCE, 2018, p. 6) ${ }^{2}$

São onze as medidas de desempenho propostas pelo ICCE: (i) satisfação dos usuários, dada pelo percentual de usuários que acreditam que o tribunal oferece justiça processual, ou seja, um serviço acessível, justo, preciso, em tempo apropriado, informado e cortês; (ii) acessibilidade, definida como o valor médio das taxas judiciais cobradas em um processo civil; (iii) taxa de atendimento à demanda ou de liberação de casos, dada pelo número de casos finalizados, expressos como uma porcentagem de casos recebidos; (iv) cumprimento de prazo, dado pela porcentagem de casos resolvidos ou finalizados dentro dos prazos estabelecidos; (v) tempo de custódia pré-julgamento, dado pelo tempo médio em que réus criminais presos aguardam julgamento; (vi) integridade dos processos, dada pela porcentagem de arquivos de casos que podem ser localizados e recuperados de maneira oportuna, atendendo aos padrões estabelecidos de precisão, organização e integridade; (vii) taxa de congestionamento, dada pela porcentagem de casos no sistema judiciário mais demorados em relação aos prazos estabelecidos; (viii) garantia da data de julgamento, dada pela proporção de eventos importantes de processamento de casos (tentativas) que são mantidos quando agendados pela primeira vez; (ix) comprometimento dos servidores, dado pelo percentual de servidores judiciais que estão produtivamente engajados na missão e no trabalho do tribunal; (x) conformidade com ordens judiciais, calculada a partir da recuperação de custas judiciais criminais e cíveis como proporção das taxas impostas; e (xi) custo por caso, dado pelo custo médio de resolução de um processo judicial, desagregado por segmento, nível e localização do tribunal, e por tipo de caso (ICCE, 2018, p. 2).

Outra orientação na produção de estatísticas judiciais é a adoção do padrão de dados abertos. Com base no Open Data Handbook, Elena (2015, p. 3) especifica as características do formato aberto, que incluem: acessibilidade (disponibilidade integral de dados, a um custo de reprodução razoável, preferencialmente acessíveis para download on-line); sustentabilidade (dados atualizados com frequência definida e processos padronizados para publicação); reutilização (formato de dados que permite a reutilização, a redistribuição e a combinação com outros conjuntos de dados - interoperabilidade); e não discriminação (o acesso aos dados não deve ser restrito a determinados propósitos ou sujeito a direitos autorais).

2 Em tradução livre: "Mensuração e gerenciamento do desempenho de tribunais é a disciplina e o processo de monitorar, analisar e usar dados de desempenho organizacional em uma base regular (idealmente em tempo real ou quase real) e contínua para fins de melhorias na eficiência e eficácia organizacional, na transparência e prestação de contas, e na confiança pública e confiança nos tribunais e no sistema de Justiça”. 
As estatísticas judiciais e a adoção de um padrão de dados para que possam ser acessados livremente somente é possível a partir da utilização de instrumentos de tecnologia da informação e de sistemas integrados que sejam capazes de dar robustez e confiabilidade às informações disponíveis. De maneira geral, é possível afirmar que a tecnologia já faz parte da grande maioria dos sistemas de Justiça e foi adotada como estratégia para melhorar a prestação jurisdicional. Nesse sentido, a tecnologia é utilizada não somente para a produção de informação sobre as atividades judiciais, mas também como mecanismo de acesso à Justiça, como é o caso dos processos judiciais digitais, formato que têm um impacto direto no tempo de tramitação dos processos; e da maior transparência e agilidade no acompanhamento dos processos, por meio das páginas digitais dos tribunais. De acordo com relatório publicado em 2017 pelo Banco Mundial sobre os resultados de reformas dos Judiciários realizadas em países como Índia, Brasil e Argentina, a tecnologia tem sido um instrumento central na modernização das instituições do sistema de Justiça e produz resultados em menor tempo e com maior impacto na medição do desempenho dessas instituições (CHEMIN, HARLEY e PANTER, 2017).

No caso brasileiro, a implementação, o uso e o desenvolvimento de tecnologia do Poder Judiciário é um foco importante de atuação do CNJ. Exemplo disso é o fato de que faz parte da Estratégia Nacional do Poder Judiciário, que trata da gestão e do planejamento do Judiciário brasileiro, o Macrodesafio Melhoria da Infraestrutura e Governança de TIC, cujo objetivo é:

[...] garantir confiabilidade, integralidade e disponibilidade das informações, dos serviços e sistemas essenciais da justiça, por meio do incremento e modernização dos mecanismos tecnológicos, controles efetivos dos processos de segurança e de riscos, assim como a otimização de recursos humanos, orçamentários e tecnológicos. (CNJ, 2018a)

Ainda no que diz respeito ao uso da tecnologia em gestão e planejamento do Judiciário, tem crescido o interesse acadêmico nessa área, com foco em estudos empíricos. Em um levantamento sobre produções acadêmicas tratando do desempenho de judiciários, Gomes e Guimarães (2013) localizaram 58 estudos empíricos, publicados entre 1992 e 2011, consultando as principais bases de periódicos - Spell; SciELO; ABI/Inform Global (ProQuest); SAGE Journal online; JSTOR Arts \& Science I Collection; SpringerLink; Emerald; Oxford Journal.

Um quinto dessas publicações trata do Judiciário brasileiro, havendo pesquisas sobre o Judiciário norte-americano, judiciários de outros países latino-americanos, de países europeus, asiáticos e africanos. Há, também, alguns estudos com perspectiva comparativa global.

Os autores observaram que o conceito de desempenho judicial é abrangente, envolvendo diferentes dimensões e níveis de análise, com os estudos comunicando-se pouco entre si. Observaram, também, que as dimensões de eficiência e celeridade são as mais comumente utilizadas para avaliar o desempenho, com foco mais no gerenciamento dos processos inter- 
nos do que nos recursos disponíveis. No que se refere ao nível de análise, o que predomina é o organizacional, com foco no desempenho de tribunais, seguido do individual, com dados referentes aos juízes.

As variáveis mais recorrentes para mensurar desempenho são os produtos da atividade judicial: processos julgados e decisões proferidas. E as variáveis mais utilizadas na explicação do desempenho são as de insumo: número de magistrados; número de servidores; recursos financeiros; quantidade e complexidade de procedimentos administrativos; perfil dos magistrados e uso de tecnologia (GOMES e GUIMARÃES, 2013, p. 389).

A maioria das pesquisas é baseada em dados secundários, sobretudo documentos e bancos de dados oficiais, daí a importância de conhecer como são produzidos os dados sobre o Judiciário brasileiro.

Dado o panorama geral sobre a construção de indicadores de desempenho da atividade judicial e a possibilidade de estudos comparados acerca do tema, como analisar o caso brasileiro? Quais avanços foram verificados e quais são os limites e desafios de nosso sistema de produção de dados que ainda precisam ser superados, no sentido de torná-lo mais transparente e instrumental? Qual o papel da tecnologia nesse caso?

\section{A PRODUÇÃo DE INFORMAÇÃo NO JUDICIÁRIO BRASILEIRO}

O Brasil está entre os países com melhor desempenho no que se refere à publicidade de estatísticas judiciais. Desde a criação do $\mathrm{CNJ}$, tem havido regularidade na publicação de estatísticas, na disponibilidade de dados agregados e na acessibilidade.

Elena (2015) afirma que, apesar de o Poder Judiciário ser uma das instituições estatais menos sujeitas ao escrutínio público na América Latina, e de não haver estratégias sistemáticas para promover a responsabilização judicial, nem políticas públicas eficientes para melhorar a qualidade dos serviços de Justiça, tem havido melhoria no que se refere a políticas de transparência e publicidade de estatísticas judiciais na região.

A autora avalia sete países (Brasil, Costa Rica, Chile, Argentina, México, Peru e Uruguai), observando a disponibilidade de dados sobre decisões judiciais, movimentação processual, orçamento e estrutura administrativa, verificando se e em que medida atendem às características de dados abertos. Cada país recebeu uma pontuação, em uma escala final que vai de 0 a 120,5. O país mais bem avaliado foi o Brasil, com 107,05 pontos, seguido pela Costa Rica, com 99,86 pontos.

Elena conclui que, embora existam políticas de transparência e publicidade de informação nos sete países, e apesar de todos eles serem membros da Open Government Partnership, nenhum deles publica todos seus dados judiciais em formato aberto. A autora afirma que a quantidade de dados judiciais disponíveis tem sido mais resultado de políticas para aumentar a transparência do que para melhorar a qualidade da prestação jurisdicional ou a accountability (ELENA, 2015, p. 9). 
Sadek, Soares e Stemler (2017) seguem na mesma linha, indicando que o Brasil está entre os países que disponibilizam estatísticas judiciais mais detalhadas. Os autores observaram que, de um total de 23 judiciários de países integrantes da Organização de Estados Ibero-americanos (OEI), em apenas 13 (Brasil, Chile, Uruguai, Paraguai, Equador, Costa Rica, Guatemala, Peru, Honduras, Nicarágua, Panamá, Colômbia e Espanha) foram identificados registros recentes e sistematizados sobre litigiosidade e movimentação processual.

O Poder Judiciário brasileiro atende em grande parte aos indicadores mínimos pautados pelos organismos internacionais, disponibilizando um conjunto considerável de variáveis e indicadores quantitativos de desempenho. O SIESPJ conta com 810 variáveis para leitura por tribunal. Integrado ao SIESPJ, o Módulo de Produtividade Mensal disponibiliza algumas dessas variáveis desagregadas por serventia judiciária e por magistrado. ${ }^{3}$

A $14^{a}$ edição do relatório Justiça em Números (CNJ, 2018b), que sistematiza os dados do SIESPJ, mostra que em 2017 tramitaram nos tribunais brasileiros 111,1 milhões de processos, o que representa 1 processo a cada 2 brasileiros. ${ }^{4}$ Ingressaram nesses tribunais 29,1 milhões de casos novos, sendo 79,7\% deles em formato eletrônico.

Foram baixados 31 milhões de processos, com uma produtividade de 1.819 processos por magistrado, considerando os 18.168 cargos providos. Em um terço dos casos baixados, o benefício da justiça gratuita foi concedido.

O ano de 2018 teve início com um passivo de 80,1 milhões de processos pendentes de decisão, sendo 39\% desse total casos de execução fiscal. Essa movimentação processual custou R $\$ 90,8$ bilhões aos cofres públicos, o que corresponde a 1,4\% do PIB, ou um custo de $\mathrm{R} \$ 437,47$ por habitante.

O relatório traz outros indicadores, incluindo: a localização da estrutura física do Poder Judiciário; o quadro geral de pessoal; receitas; taxas de recorribilidade interna e externa; tempos de tramitação processual até a sentença, até a baixa e a idade média do acervo; um índice de conciliação; os assuntos e as classes processuais mais frequentes; e um índice de produtividade comparada da Justiça (IPC-Jus), que compara o serviço prestado (processos baixados), de acordo com os recursos consumidos (quadro de pessoal, orçamento, demanda e estoque). Para o cálculo desse índice, emprega-se a técnica de análise envoltória de dados (DEA),

3 O Módulo de Produtividade Mensal pode ser acessado via painéis do CNJ, no link https://paineis.cnj. jus.br. Acesso em: 20 set. 2018.

4 O Poder Judiciário brasileiro é composto por 91 tribunais: STF; Superior Tribunal de Justica (STJ); Superior Tribunal Militar (STM); Tribunal Superior do Trabalho (TST); Tribunal Superior Eleitoral (TSE); 5 Tribunais Regionais Federais (TRFs); 24 Tribunais Regionais do Trabalho (TRTs); 27 Tribunais Regionais Eleitorais (TREs); 3 Tribunais de Justiça Militar Estaduais (TJMs); e 27 Tribunais de Justiça no âmbito da Justiça Estadual (TJs). Este artigo trata dos 90 tribunais que integram o SIESPJ, excluindo, portanto, o STF. 
identificando-se os tribunais mais eficientes, ou seja, aqueles que conseguem produzir mais baixas com a menor quantidade de recursos.

O retrato que esses indicadores delineiam é de um Judiciário lento, caro e congestionado, apesar da alta produtividade dos juízes. A litigiosidade segue crescendo (em 2009 eram 24,6 milhões de casos novos), mas o perfil dos litigantes não é identificado. Sabemos, a partir de estudos anteriores, que a litigiosidade está concentrada nas mãos de poucos e contumazes litigantes, públicos e privados, dentre os quais se destacam os órgãos da Administração Pública e as instituições financeiras (CNJ, 2011).

Sabemos, também, a partir de levantamentos populacionais, que há um contingente significativo de pessoas que não levam seus conflitos passíveis de judicialização ao sistema formal de Justiça: dados do Suplemento deVitimização de Justiça, da Pesquisa Nacional por Amostra de Domicílios (PNAD) (IBGE, 2009), mostraram que cerca de 40\% das pessoas que passaram por conflitos graves não foram ao Judiciário em busca de solução.

Outros levantamentos um pouco mais recentes, mas com cobertura e alcance amostral menores, seguem identificando esse mesmo cenário, em que parte significativa da população declara ter vivenciado situações de desrespeito a direitos passíveis de solução pela via judicial, mas o contingente dos que procuram o caminho da Justiça formal é diminuto (SÁ E SILVA, 2011; OLIVEIRA e CUNHA, 2016).

A impressão é que chegamos a 2018 praticamente com os mesmos problemas de desempenho diagnosticados nas décadas de 1990 e 2000. Antes, portanto, da Reforma do Judiciário e da instalação do CNJ. Continuamos a ter, com o empréstimo das palavras de Sadek (2004, p. 86), demandas de menos e demandas de mais.

Ou seja, de um lado, expressivos setores da população acham-se marginalizados dos serviços judiciais, utilizando-se, cada vez mais, da justiça paralela, governada pela lei do mais forte, certamente menos justa e com altíssima potencialidade de desfazer todo o tecido social. De outro, há os que usufruem em excesso da justiça oficial, gozando das vantagens de uma máquina lenta, atravancada e burocratizada. (SADEK, 2004, p. 86)

O problema de eficiência fica ainda mais evidente quando se considera a relação custo-benefício para a sociedade como um todo, dado o custo da máquina judiciária e o perfil dos litigantes: um serviço caro, atendendo predominantemente ao próprio Estado, ao mercado financeiro e a outras organizações privadas.

Esse diagnóstico é ainda mais preocupante quando recorremos às informações sobre os gastos com tecnologia no Judiciário brasileiro, que, de alguma forma, deveriam se converter em melhoria dos sistemas de informação. De acordo a $14^{a}$ edição do relatório Justiça em Números (CNJ, 2018b), desde 2009 houve um crescimento médio anual de 13,8\% nos gastos com o uso da tecnologia na gestão do Judiciário. 


\section{A teCNOlOGia E A PRODUÇÃo de INFORMAÇÃo NO JUDiCiÁRIO BRASILEIRO}

No Brasil, o uso da tecnologia nos tribunais não é uma novidade. Ao contrário, é um fenômeno anterior à aprovação da Reforma do Judiciário (EC n. 45/2004) e que, conforme já apontado, ganhou maior intensidade com a criação do CNJ. Apenas como exemplo, em relatório do Banco Mundial publicado em 2004 acerca da produção de informação sobre as atividades do Judiciário brasileiro, a informatização dos tribunais no Brasil, nas diversas áreas e instâncias, já era uma realidade desde o início dos anos 2000, apesar de não significar produção de informação mais confiável, padronização na geração de dados ou utilização desses instrumentos para a melhoria da gestão dos tribunais (CUNHA et al., 2004).

Nesse sentido, se em termos de quantidade, transparência e publicidade de dados o cenário é positivo, em termos da qualidade desses dados é preciso avançar. Os dados disponíveis hoje são melhores que os existentes há uma década, mas continuam a permitir apenas a avaliação da produtividade global do Judiciário, de tribunais e juízes, estando ainda distantes do que é necessário para possibilitar a elaboração e a avaliação de políticas públicas de melhoria da prestação dos serviços de Justiça.

A produção de dados segue o modelo clássico de avaliação de desempenho, reportando os insumos, a demanda (porta de entrada) e a resposta (porta de saída), em uma abordagem de performance instrumental, via gerenciamento do fluxo de casos, com foco em resultados quantitativos para tribunais como um todo. Recursos (financeiros, humanos, infraestrutura); volume de demandas; tempos de movimentações processuais; produtividade; e taxas de recorribilidade estão disponíveis para cada um dos tribunais, sendo possível ler apenas alguns desses indicadores por unidade judicial e para cada juiz, como o volume de casos novos, pendentes e baixados, e os índices que derivam desses dados, como a taxa de congestionamento e o índice de atendimento à demanda. São medidas muito gerais, que permitem poucos avanços para a proposta de medidas efetivas de melhoria da prestação jurisdicional.

As dimensões da avaliação de desempenho utilizadas são as de eficiência técnica (produtividade); eficiência econômica (custos); e celeridade (tempo). Não há medidas de efetividade, como o cumprimento de decisões. O que mais se aproxima disso é o quantitativo de processos baixados na fase de execução, mas não temos detalhamento sobre valores pagos / recebidos, nem o perfil detalhado dos casos em termos de partes e assuntos. Tampouco é possível separar a quantidade de processos findos (baixados) em decorrência do cumprimento da decisão daqueles baixados em razão de prescrição.

Faltam, também, indicadores de qualidade, e o proxy mais utilizado para isso, o indicador de reforma de decisões, parou de ser publicado por inconsistência e imprecisão dos dados, uma vez que não há um movimento padrão para extrair essa informação. Desse modo, tribunais diferentes contabilizavam como reforma (recurso provido, total ou em parte) aspectos diferentes, com alguns classificando nessa categoria a mera revisão de honorários advocatícios. Em 2014, ano do último relatório Justiça em Números que traz esses dados (CNJ, 2015), o indicador de reforma no $2^{\circ}$ grau da Justiça estadual variou de 4,4\%, para o Tribunal de Justiça 
do Estado do Acre (TJAC), até 71,2\%, para o Tribunal de Justiça do Estado de Goiás (TJGO). O Tribunal de Justiça do Estado de São Paulo (TJSP) contabilizou 12\% de reforma, e o Tribunal de Justiça do Estado do Rio Grande do Sul (TJRS), 20\%.

O CNJ vem utilizando as estatísticas judiciais para identificar alguns gargalos - aplicando modelos como o DEA, que resulta no já citado IPC-Jus - e vem perseguindo uma agenda eficientista, com a preocupação de gerir o volume de litígios, mais do que lidar com suas causas. Para isso, seria necessário produzir dados mais detalhados, desagregados e com maior consistência sobre o perfil das demandas e das partes. Hoje só estão disponíveis quantitativos de processos por classe e assunto, e, como esses dados são gerados de maneira agregada, é impossível cruzar essas informações.

A principal política judiciária para lidar com a judicialização excessiva têm sido as metas de produtividade dos juízes, voltadas a desafogar o Judiciário. ${ }^{\mathbf{5}}$ Contudo, se observarmos que o passivo de processos só aumenta ano a ano, tendo crescido 32\% entre 2009 e 2018, verificamos que essa política não tem sido efetiva, sugerindo que os indicadores de desempenho judicial não têm sido utilizados para propor políticas capazes de sanar as principais deficiências na prestação jurisdicional.

Há uma série de fatores que precisam ser considerados para entender por que o cenário do desempenho judicial mudou tão pouco, e sob alguns aspectos parece até mesmo ter piorado. Um deles é a necessidade de qualificação das estatísticas judiciais: há problemas quanto à forma como os dados são coletados; sua organização, consistência e confiabilidade; e sua instrumentalidade na administração dos tribunais.

Os dados existentes sobre desempenho judicial ainda estão muito distantes do que é necessário e realizável, dada a tecnologia hoje existente, para possibilitar a elaboração e a avaliação de políticas públicas de melhoria e acompanhamento da prestação dos serviços de Justiça.

\section{I QUALIDADE DOS DADOS: LIMITAÇÕES E DESAFIOS}

As principais limitações que a produção de estatísticas judiciais apresenta estão relacionadas à forma de geração dos dados. Apesar da criação do CNJ em 2005, e da centralização na publicização dos dados, não houve uma mudança significativa na maneira como os dados

$5 \quad$ Os dados compilados nos relatórios Justiça em Números orientam a elaboração de diagnósticos e de metas aplicáveis ao Poder Judiciário Nacional. O CNJ acompanha o alcance dessas metas pelos diferentes tribunais ano a ano, a partir do Relatório de Metas, disponível no link: http: / / www.cnj.jus.br/gestao-e-planejamento/metas (CNJ, 2018c). Uma vez que o interesse do presente artigo não está na gestão do Judiciário em si, mas sim na produção de estatísticas judiciais que permitam a elaboração de melhores diagnósticos (no sentido de mais precisos e instrumentais), voltados à orientação de ações para o aperfeiçoamento da prestação jurisdicional, as metas não são objeto de análise aqui. Para uma discussão sobre metas e governança judicial, ver, entre outros, Ruschel, Silva e Rover (2010). 
são extraídos e consolidados: isso continua a ser realizado previamente por tribunal, remetendo-se ao CNJ de maneira agregada, inicialmente por meio de planilhas e agora por meio de formulário eletrônico.

Os problemas se iniciam na arquitetura do sistema de informática dos tribunais - tecnologia -, que foi planejado para gerar dados individuais sobre cada processo em andamento, e não variáveis padronizadas sobre o conjunto dos processos. Essa característica é um limitador do ponto de vista estatístico, pois não permite a geração espontânea de dados globais - como o volume do contencioso no que diz respeito à matéria, às partes, à duração média de cada feito e ao número de recursos gerados por pedido. A maneira como os dados são gerados dificulta tanto o acompanhamento do percurso de um processo dentro do Judiciário quanto o conhecimento da solução que o tribunal confere para cada tipo de caso.

Nesse sentido, é possível afirmar que o uso da tecnologia nos tribunais, ou seus sistemas de informática, não aconteceu a partir do pressuposto de uma nova gestão pública, em que a transparência e a eficiência decorrem da racionalização dos processos administrativos, que só é possível quando são: (i) identificadas as especificidades de cada processo; (ii) padronizadas as classificações dos processos; e (iii) centralizadas a produção das informações sobre os processos. Isso sem falar na publicização e na transparência das informações, a fim de que a gestão pública seja acessível a uma gama cada vez maior de cidadãos (LIMA, FRAGA e OLIVEIRA, 2016). Ao contrário, a tecnologia nos tribunais brasileiros tem servido, em sua maioria, muito mais como uma política de modernização de seus recursos materiais do que efetivamente como tecnologia da informação e comunicação.

Por esse ângulo, o relatório do Banco Mundial de 2004, já indicado, mostrava que a tecnologia e o uso de computadores ou a digitalização dos processos não produziam efeito no tempo dos processos - até porque estes não eram mensurados -, na administração da Justiça ou na transparência das atividades do Judiciário, já que tinham como destinatário principal e imediato os advogados, que utilizavam e utilizam o sistema digital simplesmente para acompanhar o andamento processual (BANCO MUNDIAL, 2004).

A partir da criação do CNJ, buscou-se trazer um olhar sobre a importância da tecnologia e das estatísticas na gestão dos tribunais. Em 2006, foi criado o Banco de Soluções do Poder Judiciário, via Resolução CNJ n. 12 (de 14 de fevereiro de 2006), para definir os padrões de interoperabilidade a serem utilizados no Poder Judiciário. Em decorrência dessa resolução, foi acordado, em 2009, entre STF, CNJ, STJ, Conselho da Justiça Federal (CJF), TST, Conselho Superior da Justiça do Trabalho (CSJT), Advocacia-Geral da União (AGU) e Procuradoria- Geral da República (PGR), o Modelo Nacional de Interoperabilidade (MNI). O MNI estabelece padrões para o intercâmbio de informações de processos judiciais. Assim, de acordo com o MNI, os tribunais precisam ser capazes de extrair, minimamente, as seguintes informações, com consistência, para processos baixados e em tramitação: número do processo; unidade judiciária; nome das partes; CPF ou CNPJ das partes; código e descrição da classe processual, do assunto e da movimentação (movimentos). 
Um dos estímulos à adoção do MNI pelos tribunais foi o Selo Justiça em Números, ${ }^{6}$ uma premiação aos tribunais que conseguissem gerar essas informações mínimas por processo (Portaria CNJ n. 186, de 17 de outubro de 2013). Essa premiação fez que a preocupação com a qualidade e fidedignidade dos dados estatísticos passasse dos técnicos para a alta administração dos tribunais. Porém, apesar de o Selo existir desde 2013, nem todos os tribunais disponibilizam os dados por processo. ${ }^{7}$ Os dados existentes não são públicos, nem são utilizados para calcular os indicadores do Justiça em Números.

Em 2008, via Resolução n. 65, de 16 de dezembro de 2008, o CNJ estabeleceu a numeração única para os processos judiciais, padronizando e fixando o número dos processos ao longo de toda sua tramitação no Poder Judiciário, independentemente de mudança de instância. Essa solução facilitaria o acompanhamento do percurso dos processos se as estatísticas fossem produzidas tendo o processo como unidade básica de análise, e não o tribunal. Apesar disso, a mesma numeração em diferentes instâncias não é tratada de maneira igual pelos 91 tribunais brasileiros. ${ }^{8}$

Como decorrência direta dessa limitação, a estimativa do tempo de duração dos processos é feita com base no tempo médio até a sentença, no tempo médio até a baixa e na duração média dos processos pendentes, seguindo uma divisão unicamente por etapas de conhecimento e execução, separando os processos por instância e ramo de Justiça. Esse indicador não permite avaliações mais precisas para o direcionamento de políticas de combate à morosidade. Para isso, seria mais profícuo trabalhar com quantis, por agrupamento de processos semelhantes, segundo classe, assunto e perfil das partes. Para possibilitar essas análises seria necessário utilizar dados desagregados, considerando como unidade de análise o processo, e não o tribunal.

Esse acesso ainda é difícil porque, embora $4 / 5$ dos processos novos tramitem em formato eletrônico, não há padronização no formato dos sistemas. A Resolução CNJ n. 185/2013, que instituiu o Sistema de Processo Judicial Eletrônico (PJe), não previu a obrigatoriedade do formato, havendo outros sistemas de tramitação eletrônica nos tribunais. Além disso, apesar de a Resolução CNJ n. 185/2013 indicar como uma das funções da implantação do PJe "o fornecimento de dados essenciais à gestão das informações necessárias aos diversos órgãos de supervisão, controle e uso do sistema judiciário”, o que temos hoje é a existência de plataformas eletrônicas diferentes, nos diversos órgãos do Poder Judiciário, que têm como objetivo principal facilitar o acompanhamento processual dos casos em andamento nesses órgãos.

6 Para detalhamento do Selo Justiça em Números, conferir CNJ (s.d.).

7 De acordo com Barbão e Oliveira (2017, p. 27), para 2015, por exemplo, os tribunais de justiça estadual de São Paulo e Rio Grande do Norte e os tribunais federais das $1^{\text {a }}$ e $3^{\mathrm{a}}$ regiões não forneceram os dados.

8 Ver nota 4. 
De acordo com dados do $14^{\circ}$ relatório Justiça em Números (CNJ, 2018b, p. 90), em 2017 existiam pelo menos outros oito sistemas eletrônicos em uso nos tribunais estaduais e unidades judiciárias vinculadas (e-SAJ, Themis, Tucujuris, e-Proc, SCPV, UDI, Projudi, Ejud).

Essa diversidade de formatos no uso da tecnologia para a produção de informação das atividades dos tribunais gera desafios para a parametrização, no sentido de transformar os dados: dispersos em várias bases de dados, com códigos e regras de codificação diferentes, é preciso padronizar, validar e consolidar tudo em uma base única para extração de informações.

Assim, é possível afirmar que o uso de tecnologia no Judiciário brasileiro não atende à demanda por produção de informação sobre a atividade judiciária, tampouco favorece o uso dessa informação como instrumento de gestão e melhoria da prestação jurisdicional. Além disso, a diversidade de sistemas eletrônicos, em vez de contribuir para a democratização do acesso à Justiça, tem produzido obstáculos até mesmo para os usuários desses sistemas, que precisam criar cadastros distintos para acessar cada uma das plataformas dos diferentes tribunais e, muitas vezes, dispor de diferentes softwares para poder acessar essas plataformas (AQUINO, 2019).

Além de limitar o tipo de uso que se pode fazer dos dados, por não ser possível uma série de cruzamentos, a forma de geração dos dados ou do emprego da tecnologia provoca, também, problemas de inconsistência. Um dos mais notórios é o volume de processos pendentes. Se no ano de 2017 havia um passivo de 79,8 milhões de processos não finalizados em 2016; ingressaram 29,1 milhões de casos novos; e foram baixados 31,0 milhões de casos, o balanço final deveria ser de 77,9 milhões de processos pendentes, e não os 80,1 milhões reportados. A diferença é de 2,2 milhões de processos. A diferença pode parecer pequena, mas deveríamos ter condições de contar com precisão o número de processos.

Em 2017, o CNJ passou a contabilizar os processos já baixados que retornam à tramitação, por qualquer motivo, sem figurar como caso novo. Foram cerca de 600 mil casos reativados. Ainda assim, resta uma diferença substancial, com o total de casos pendentes seguindo superestimado.

Essa diferença é devida, possivelmente, ao que é contabilizado como caso novo e à forma como esses dados são extraídos por cada tribunal. O CNJ disponibiliza glossários, regras de parametrização e scripts do PJe detalhados para aferição de cada variável, mas não há garantia de que todas as extrações realizadas pelos tribunais estejam corretas.

É preciso considerar, ainda, as especificidades na contabilização de caso novo; nem todas as classes processuais são incluídas e os processos baixados na fase de conhecimento são contabilizados como novos, mais uma vez, se ingressam na fase de execução. A contabilização segue a lógica de mensuração de esforço de trabalho dos magistrados, que podem ser beneficiados ou penalizados de acordo com sua produtividade - em vez de seguir a lógica de acompanhamento da qualidade da prestação jurisdicional, a partir da trajetória do processo.

Outras inconsistências ocorrem por conta do processo de cadastramento dos casos. Processos mal-autuados, classificados em categorias indevidas, que recebem movimentos e assuntos 
lançados de maneira inadequada, contribuem para gerar problemas de consistência, prejudicando a sistematização dos dados. É praticamente impossível saber hoje, por exemplo, a quantidade exata de processos que reivindicam acesso a uma medicação específica, em uma das frentes que vêm sendo discutidas no campo da judicialização da saúde. Pesquisadores interessados nessa temática têm lançado mão de estratégias diversas para obter acesso ao total de processos, sendo a pesquisa nas páginas eletrônicas individuais de cada um dos tribunais o principal recurso quando se trata de acompanhar decisões de primeira instância (sentenças).

Da mesma maneira, por mais que existam esforços em verificar os litigantes recorrentes, as análises produzidas pelas pesquisas empíricas que utilizam os sistemas digitais dos tribunais trazem apenas aproximações da realidade. Isso porque a tecnologia utilizada no Judiciário não é capaz de produzir essa informação e, assim, dar consistência aos dados. O que o uso da tecnologia tem feito nos tribunais brasileiros é apenas contabilizar casos de diferentes complexidades, com causas e consequências diversas dentro e fora dos tribunais, que, por sua vez, aprofundam o desconhecimento sobre o impacto da Justiça no dia a dia do cidadão, sobre o acesso à Justiça e sobre a imparcialidade da lei.

Embora o CNJ tenha criado as Tabelas Processuais Unificadas, para dar uniformidade à taxonomia e terminologia de classes, aos assuntos e movimentações processuais no Poder Judiciário (Resolução CNJ n. 14, de 18 de dezembro de 2007), seu uso ainda não é universal; e mesmo entre as unidades judiciárias que utilizam as tabelas ainda há equívocos, com critérios empregados indiscriminadamente para a classificação dos processos. Além disso, falta padronização no cadastro das partes, e em muitos casos essa informação está ausente. Falta, também, sistematicidade no corpo das decisões - por exemplo, quando se trata dos valores pagos aos jurisdicionados e, no caso de reforma de decisão, qual o teor da revisão, ou seja, o que exatamente foi alterado.

Aqui, mais uma vez, é preciso ressaltar que a existência de sistemas digitais incapazes de produzir informações automaticamente e a simples criação das Tabelas Processuais Unificadas, sem que antes tenha havido debate sobre a importância e a utilidade dessas informações, limita o alcance do uso da tecnologia, muitas vezes mascarando informações que poderiam ser utilizadas para a construção de novas políticas públicas na área, melhorando efetivamente a prestação jurisdicional do Estado. Santiago Varella (2017), em artigo recente sobre a produção de indicadores da Justiça, mostra que não somente é preciso melhorar a produção de dados sobre o Judiciário, mas é também fundamental que haja debate e troca entre as instituições do sistema de Justiça, a academia e os institutos de pesquisa a respeito do uso dos dados, seu alcance e sua limitação.

Na área criminal, foi criado o Banco Nacional de Mandados de Prisão (BNMP 2.0, instituído e regulamentado pela Resolução CNJ n. 251, de 4 de setembro de 2018), que procura contabilizar e detalhar os processos criminais que envolvem penas privativas de liberdade. Resta verificar em que medida os tribunais irão fornecer informações para esse registro e se esses dados serão confiáveis. 
A tecnologia, nesse sentido, deve ser um instrumento para melhoria, e não para tornar as instituições públicas reféns de sistemas de informática que sustentam um discurso de modernidade, mas que, na verdade, não contribuem para a transformação das políticas públicas.

O CNJ tem estabelecido políticas voltadas à padronização de informações, mas sua adoção pelos tribunais tem se dado de modo e em graus variados, com pouca capacidade de enforcement. A crítica feita por Sadek (2006) ao excesso de descentralização e autonomia administrativa do Poder Judiciário permanece válida, com esse poder levando a suas últimas consequências o federalismo.

Por outro lado, é preciso também levar em conta em que medida o uso da tecnologia no Judiciário por meio da introdução de computadores e sistemas digitais como instrumento de trabalho vem produzindo um novo tipo de magistrado. De acordo com a análise de Fernando Fontainha (2012) em seu trabalho Juízes empreendedores: um estudo a partir da informatização dos tribunais brasileiros, se em um primeiro momento o uso de computadores e da tecnologia nos tribunais tinha como objetivo facilitar o trabalho dos juízes, reduzindo o tempo dos processos, melhorando a prestação dos serviços e a satisfação dos usuários, impactando positivamente a prestação jurisdicional, tal estratégia levou ao surgimento de um novo tipo de juiz, voltado para o que o autor chama de "juiz-empreendedor".

O juiz-empreendedor tem como interesse fundamental a gestão dos tribunais e, ao fim e ao cabo, o cumprimento de metas quantitativas impostas pelo CNJ, em vez de se atentar à atividade para a qual foi selecionado e treinado, qual seja, a prestação jurisdicional (FONTAINHA, 2012).

Apesar da existência de processos digitais e do uso de ferramentas como protocolos eletrônicos e videoconferências, ou do aplicativo de mensagens WhatsApp para realizar intimações judiciais, o foco está na gestão das atividades, e não no impacto que o Judiciário tem na sociedade.

No que se refere à produção de indicadores de desempenho judicial, depois de mais de uma década da instalação do CNJ, continuamos, em essência, produzindo dados agregados sobre o volume de casos processados pelo Poder Judiciário, que buscam exclusivamente quantificar os casos, não sendo possível identificar as partes ou o perfil dos tipos de casos mais frequentes ou que causam maior impacto. O objetivo da estatística judicial no Brasil parece continuar a ser o de acompanhar o volume de trabalho dos juízes e dos tribunais, não tendo se transformado em um instrumento importante no sentido de informar e organizar a elaboração de políticas públicas na área, nem a avaliação de medidas adotadas. A integração dos sistemas e sua capacidade de produzir informações de maneira automática e confiável são essenciais para a evolução e a melhoria dos serviços públicos dentro do Judiciário brasileiro.

Embora existam dificuldades reconhecidas para se mensurar o desempenho não apenas do Judiciário, mas do setor público como um todo (NOGUEIRA, 2010), é preciso avançar na produção de dados mais consistentes e detalhados, e que de fato possam balizar políticas públicas efetivas para os problemas há décadas diagnosticados. 
Ainda que se considere apenas o critério de eficiência, área em que a produção de estatísticas mais avançou, com o CNJ produzindo, inclusive, um indicador sintético de desempenho (o IPC-Jus), não parece ter havido melhoria concreta no desempenho dos tribunais a partir de seus resultados. Conforme aponta Yeung (2018), a maioria dos tribunais estaduais inicialmente apontados como ineficientes, a partir do emprego de modelos DEA, continua ineficiente após vários anos. Segundo a autora, juízes e mesmo gestores do CNJ não parecem ter captado o verdadeiro valor da análise de eficiência, pois, embora defendam a agenda do aumento de eficiência, as ações e políticas parecem adotadas por "tentativas e erros", sem uma análise das causas da ineficiência disseminada (YEUNG, 2018, p. 8).

Essa constatação vai ao encontro do que Lima (2008) observou sobre a produção de estatísticas de segurança pública no Brasil, no sentido de assinalar que a produção de dados pode gerar uma ilusão de transparência, ou uma “opacidade”.

O aumento da quantidade de dados produzidos, advindo da modernização tecnológica do Estado, provoca, por sua vez, a opacidade do excesso de exposição e permite que discursos de transparência sejam assumidos mas não provoquem mudanças nas regras e práticas de governo [...] a redefinição dos papéis de tais estatísticas e a superação desse quadro têm menos relação com aspectos técnicos, que são controláveis e dependem da tomada de decisões, e, mais, com aspectos políticos que deem conta de atribuir responsabilidades, evitar conflitos de competência e definir o significado e o sentido dos dados necessários às ações democráticas no campo da justiça e da segurança pública no Brasil. (LIMA, 2008, p. 69)

No caso específico das estatísticas de movimentação processual do Poder Judiciário, é preciso vontade política para impor uma transformação na lógica de produção e publicação dos dados, que precisam ser desagregados por processo e encaminhados no padrão já existente do MNI, no sentido de permitir qualificar melhor essas estatísticas e transformá-las em informações e conhecimentos úteis.

Ao mesmo tempo, mudanças em termos técnicos precisam ser implementadas, tanto no sentido de aperfeiçoamento das variáveis, da forma como se contabilizam casos novos, por exemplo, quanto na promoção da qualidade dos registros (protocolo) - além de políticas de treinamento dos servidores, até mesmo do desenvolvimento e emprego de técnicas de text mining para verificar a qualidade dos registros e desenvolver classificadores automáticos. Para tanto, parece ser necessária uma nova concepção no quadro de recursos humanos no Judiciário, incorporando os servidores na gestão dos tribunais, tarefa que hoje é feita de maneira prioritária e que consome a maior parte do tempo dos magistrados, mantendo a mesma situação diagnosticada em pesquisas realizadas no início da década de 2000 (BANCO MUNDIAL, 2004).

Vivemos a efervescência do big data, havendo tecnologia disponível para aumentar a qualidade e a consistência da informação judicial, e também para melhorar o acesso. O Poder 
Judiciário não dispõe de application programing interface (API) para facilitar o acesso do público às informações processuais, mantendo e privilegiando o acesso individual de cada processo por advogados, partes, magistrados ou pesquisadores.

Por fim, não basta o investimento na produção de estatísticas de movimentação processual e de dados administrativos. Como sabido, a avaliação de desempenho judicial envolve variáveis internas e externas, objetivas e subjetivas. A dimensão da percepção do desempenho do Poder Judiciário precisa ser incorporada. Seja na perspectiva de mensuração de atributos judiciais (STAATS, BOWLER e HISKEY, 2005), com base nas opiniões daqueles diretamente envolvidos com o sistema legal - advogados, servidores e partes -, seja na perspectiva da satisfação com o atendimento recebido e o serviço prestado.

Indicadores de desempenho e estatísticas não são perfeitos, não são isentos de vieses, e sempre constituirão uma aproximação e uma representação da realidade. Mas quanto mais detalhadas e desagregadas forem as informações, mais próximas da realidade se tornam e mais instrumentais para gestão de políticas públicas.

\section{CONCLUSÃo}

O Brasil tem uma tradição de produção de informação sobre o Judiciário. Esses dados já foram trabalhados no século XX pelo IBGE, que em alguns de seus anuários trazia informações detalhadas sobre os processos judiciais. A partir do final da década de 1990, estimulada pelo processo de modernização do Estado, via incorporação de paradigmas da nova gestão pública, e nos anos 2000, pela aprovação da EC n. 45 / 2004 e pela criação do CNJ, a estatística judicial vinculada ao uso da tecnologia ganhou impulso adicional nessa área.

A digitalização dos processos, o uso de sistemas digitais para o acompanhamento processual e a institucionalização das páginas eletrônicas dos tribunais já são uma realidade no Judiciário brasileiro. Porém, o foco principal do uso da tecnologia nesses casos não é a melhoria da prestação jurisdicional ou mesmo a análise, discussão e produção de políticas públicas a fim de melhorar a qualidade do serviço prestado pela instituição e a satisfação e confiança do cidadão.

Ao privilegiar a produção de dados para métricas quantitativas da eficiência dos tribunais com dados principais de entrada e saída dos processos no sistema, sem se ater às especificidades e complexidades dos casos, ao perfil das partes que utilizam o Judiciário e à forma pela qual ele é utilizado, o uso da tecnologia nos tribunais não vem acompanhando o movimento para o emprego de big data como instrumento de monitoramento efetivo das atividades do Judiciário e das demais instituições do sistema de Justiça.

Apesar dos esforços do CNJ para centralizar e uniformizar a coleta de dados, impulsionando políticas a fim de que as instituições do sistema de Justiça possam trocar informações e avançar no sentido de garantir que os dados sejam mais confiáveis e robustos, o discurso de modernização dos tribunais a partir do uso de tecnologia e produção de dados permanece o mesmo desde o início da década de 2000, tendo envelhecido consideravelmente. 
É como se atualmente as políticas na área estivessem simplesmente atualizando o atraso, ao não observar a necessidade de mudança do foco dos usuários dessas informações, que podem e devem partir de um paradigma que não esteja simplesmente fincado na ideia de eficiência, como aumentar o número de casos resolvidos em relação aos casos novos. É preciso avançar, incorporando a ideia de qualidade, para saber exatamente o que os servidores e juízes estão produzindo em termos de serviços públicos e do exercício de poder do Estado, o qual foi a eles concedido.

Rever a gestão da administração da Justiça, não como um fim em si mesma, mas como princípio norteador para maior segurança jurídica, previsibilidade de decisões e resultados eficazes, discutindo, compartilhando e revendo as formas de coleta, manipulação e publicização dos dados, que devem ser objeto de discussão e análise por profissionais de diferentes áreas de conhecimento, é essencial para que possamos fazer que a tecnologia esteja a favor da melhoria da prestação jurisdicional, e não o contrário.

\section{AGRADECIMENTOS}

As autoras agradecem o apoio financeiro da Fundação de Amparo à Pesquisa do Estado de São Paulo (Fapesp2018/00395-9) e as sugestões e críticas dos pareceristas anônimos.

\section{REFERÊNCIAS}

AMARILES, David Restrepo. Transnational Legal Indicators: The Missing Link in a New Era of Law and Development Policy. In: FORTES, Pedro; BORATTI, Larissa; PALACIOS, Andres; DALY, Tom (eds.). Law and Policy in Latin America: Transforming Courts, Institutions, and Rights. Palgrave Macmillan, 2016. p. 95-111.

AQUINO, J. C. G. X. Processos digitais e o direito de acesso à Justiça: entraves com sistemas podem prejudicar usuários. Folha de S.Paulo. São Paulo, 8 fev. 2019. Disponível em: https: / /www1.folha.uol. com.br/opiniao/2019/02/processos-digitais-e-o-direito-de-acesso-a-justica.shtml. Acesso em: 10 ago. 2019.

BANCO MUNDIAL. Brazil Making Justice Count Measuring and Improving Judicial Performance in Brazil. Report, n. 32789-BR. Washington D.C.: Poverty Reduction and Economic Management Unit - 
Latin America and the Caribbean Region. 30 dez. 2004. Disponível em: http: / / documents.worldbank. org/curated/en/625351468017065986/pdf/327890REPLACEM10ASOPREVIOUSORECORD1.pdf. Acesso em: 24 jan. 2019.

BARBÃO, Jaqueline; OLIVEIRA, Fabiana Luci de. Retrato do Cadastro Nacional de Condenados por Ato de Improbidade Administrativa e por A to que Implique Inelegibilidade (CNCIAI). Revista CNJ, n. 2, p. 24-33, 2017.

BURKI, Shahid Javed; PERRY, Guillermo E. Beyond the Washington Consensus: Institutions Matter (English). Washington D.C.: World Bank, 1998. [World Bank Latin American and Caribbean Studies: Viewpoints]. Disponível em: http://documents.worldbank.org/curated/en/556471468265784712/ Beyond-the-Washington-Consensus-institutions-matter. Acesso em: 23 jan. 2019.

BUSCAGLIA, Edgardo; DAKOLIAS, Maria. Comparative International Study of Court Performance Indicators: A Descriptive and Analytical Account. Washington D. C.: The World Bank: The International Bank for Reconstruction and Development, 1999.

CHEMIN, Matthieu; HARLEY, Georgia; PANTER, Elaine Rene Elizabeth. What Works? Examples of Empirically Proven Justice Reforms. Washington, D.C.: World Bank Group, 2017. Disponível em: http: / / documents. worldbank.org/curated/en/506611513850612331/What-works-examples-ofempirically-proven-justice-reforms. Acesso em: 23 jan. 2019.

CONSELHO NACIONAL DE JUSTIÇA (CNJ). Histórico Selo Justiça em Números. [s.d.]. Disponível em: http: //www.cnj.jus.br/pesquisas-judiciarias/selo-justica-em-numeros. Acesso em: 20 set. 2018.

CONSELHO NACIONAL DE JUSTIÇA (CNJ). Relatório de acompanhamento da estratégia nacional: 2016/2017. Brasília: CNJ, 2018a. Disponível em: https://www.cnj.jus.br/wp-content/uploads/2017/ 05/43c48f805354b9f7ce7c9e3e581ff3f3.pdf. Acesso em: 21 jan. 2020.

CONSELHO NACIONAL DE JUSTIÇA (CNJ). Justiça em números 2018: ano-base 2017. Brasília: CNJ, 2018b. Disponível em: https: / / www.cnj.jus.br/wp-content/uploads/conteudo/arquivo/2018/08 / 44b7368ec6f888b383f6c3de40c32167.pdf. Acesso em: 21 jan. 2020.

CONSELHO NACIONAL DE JUSTIÇA (CNJ). CNJ em números: 2018. Brasília: CNJ, 2018c. Disponível em: https://wwwh.cnj.jus.br/pesquisas-judiciarias/cnj-em-numeros. Acesso em: 12 ago. 2019.

CONSELHO NACIONAL DE JUSTIÇA (CNJ). Justiça em números 2015: ano-base 2014. Brasília: CNJ, 2015. Disponível em: https://www.cnj.jus.br/wp-content/uploads/conteudo/arquivo/2016/07/ 23fa2e5e06f732d0bb353d2747de333e.pdf. Acesso em: 21 jan. 2020. 
CONSELHO NACIONAL DE JUSTIÇA (CNJ). Os 100 maiores litigantes. Brasília: CNJ, 2011. Disponível em: https://www.cnj.jus.br/wp-content/uploads/2011/02/100_maiores_litigantes.pdf. Acesso em: 21 jan. 2020.

CUNHA, Luciana Gross. Indicadores de desempenho do Judiciário: como são produzidos e qual a sua finalidade. Cadernos FGV Projetos, v. 12, p. 41-45, 2010.

CUNHA, Luciana Gross. Rule of Law and Development: The Discourses on Institutional Reforms in the Justice System. DIREITO GV: Working Papers, n. 21, jun. 2008. Disponível em: http:/ /bibliotecadigital. fgv.br/dspace/handle/10438/2835. Acesso em: 22 jan. 2019.

CUNHA, Luciana Gross et al. O sistema de justiça brasileiro, a produção de informações e sua utilização. Cadernos DIREITO GV, v. 1, n. 4, jun. 2004. Disponível em: http://hdl.handle.net/10438/2805. Acesso em: 10 ago. 2019.

DAKOLIAS, Maria. Court Performance Around the World: A Comparative Perspective. Washingon, D.C.: The World Bank: The International Bank for Reconstruction and Development, 1999.

DOMINGO, Pilar; SIEDER, Rachel (eds.). Rule of Law in Latin America: The International Promotion of Judicial Reform. London: Institute of Latin American Studies, University of London, 2001.

ELENA, Sandra. Open Data for Open Justice: A Case Study of the Judiciaries of Argentina, Brazil, Chile, Costa Rica, Mexico, Peru and Uruguay. In: OPEN DATA RESEARCH SYMPOSIUM. Center for the Implementation of Public Policies Promoting Equity and Growth. Ottawa, Canada, 27 maio 2015. Disponível em: http:/ / www.opendataresearch.org/dl/symposium2015/odrs2015-paper10.pdf. Acesso em: 20 set. 2018.

FONTAINHA, Fernando de Castro. Juízes empreendedores: um estudo a partir da informatização dos tribunais brasileiros. Rio de Janeiro: Lumen Juris, 2012.

GOMES, Adalmir de Oliveira; GUIMARÃES, Tomás de Aquino. Desempenho no Judiciário: conceituação, estado da arte e agenda de pesquisa. Revista de Administração Pública. Rio de Janeiro, v. 47, n. 2, p. 379 $-401,2013$.

INTERNATIONAL CONSORTIUM FOR COURT EXCELLENCE (ICCE). Global Measures of Court Performance. Melbourne: Secretariat for the International Consortium for Court Excellence. 2018. Disponível em: http: / / www.courtexcellence.com/ /media/Microsites/Files/ICCE/Global\%20Measures \%20Pre-Publication\%20-\%20Sep\%202018.ashx. Acesso em: 21 jan. 2020. 
INSTITUTO BRASILEIRO DE GEOGRAFIA E ESTATÍSTICA (IBGE). Características da vitimização e do acesso à justiça no Brasil. PNAD, 2009. Disponível em: https: / biblioteca.ibge.gov.br/visualizacao/ livros/liv47311.pdf. Acesso em: 21 jan. 2020.

LIMA, Daniella Munhoz da Costa; FRAGA, Valderez Ferreira; OLIVEIRA, Fátima Bayma. O paradoxo da reforma do Judiciário: embates entre a nova gestão pública e a cultura organizacional do jeitinho. Revista de Administração Pública. Rio de Janeiro, v. 50, n. 6, p. 893-912, dez. 2016. Disponível em: http: / / www.scielo.br/scielo.php?script $=$ sci_arttext\&pid=S0034-76122016000600893\&lng=pt\&nrm=iso. Acesso em: 24 jan. 2019.

LIMA, Renato Sérgio de. A produção da opacidade: estatísticas criminais e segurança pública no Brasil. Novos Estudos - CEBRAP, n. 80, p. 65-69, 2008.

NOGUEIRA, José Marcelo Maia. A gestão do Poder Judiciário: uma análise do sistema de mensuração de desempenho do Judiciário brasileiro. Dissertação (Mestrado) - Escola de Administração de Empresas de São Paulo, Fundação Getulio Vargas. São Paulo, 2010.

OLIVEIRA, Fabiana Luci de; CUNHA, Luciana Gross. Medindo o acesso à Justiça Cível no Brasil. Opinião Pública, v. 22, n. 2, p. 318-349, 2016.

RUSCHEL, Aírton José; SILVA, Cláudio Eduardo Regis de Figueiredo; ROVER, Aires José. O Governo Eletrônico na gestão do Judiciário. Revista da ESMESC - Escola Superior da Magistratura do Estado de Santa Catarina. Florianópolis, v. 16, n. 23, p. 25-44, 2010.

SÁ E SILVA, Fábio. SIPS: Sistema de Indicadores de Percepção Social: Justiça. Brasília, Ipea, 2011. Disponível em: http://www.ipea.gov.br/portal/images/stories/PDFs/SIPS/110531_sips_justica. pdf. Acesso em: 20 set. 2018.

SADEK, Maria Tereza Aina. Judiciário: mudanças e reformas. Estudos Avançados, v. 18, n. 51, p. 79-101, 2004.

SADEK, Maria Tereza Aina. A produção acadêmica sobre o sistema de justiça. Cadernos Direito GV. São Paulo, v. 2, n. 3, p. 29-33, 2006.

SADEK, Maria Tereza Aina; OLIVEIRA, Fabiana Luci de. Estudos, pesquisas e dados em justiça. In: OLIVEIRA, Fabiana Luci de (org.). Justiça em foco: estudos empíricos. Rio de Janeiro: FGV, 2012, p. 15 -61. v. 1.

SADEK, Maria Tereza Aina; SOARES, Gabriela; STEMLER, Igor. Judiciário e transparência: Justiça em Números do Brasil se destaca com ampla diversidade de informações. Jota, 12 dez. 2017. Disponível 
em: https://www.jota.info/opiniao-e-analise/artigos/judiciario-e-transparencia-12122017. Acesso em: 20 set. 2018.

STAATS, Joseph; BOWLER, Shaun; HISKEY, Jonathan. Measuring Judicial Performance in Latin America. American Politics \& Society, v. 47, n. 4, p. 77-106, 2005.

VARELLA, Santiago. Estatística, planejamento e políticas judiciárias: ainda um debate de surdos. Jota, $1^{\circ}$ mar. 2017. Disponível em: https: / / www.researchgate.net/publication/315716525_Estatistica_ planejamento_e_politicas_judiciarias_ainda_um_debate_de_surdos. Acesso em: 24 jan. 2019.

YEUNG, Luciana. Measuring Efficiency of Brazilian Courts: One Decade Later. 21 jun. 2018. Disponível em: https://ssrn.com/abstract=3200588. Acesso em: 20 set. 2018.

\section{COMO CITAR ESTE ARTIGO:}

OLIVEIRA, Fabiana Luci de; CUNHA, Luciana Gross. Os indicadores sobre o Judiciário brasileiro: limitações, desafios e o uso da tecnologia. Revista Direito GV, v. 16, n. 1, jan./abr. 2020, e1948. doi: http://dx.doi.org/10.1590/ 2317-6172201948.

\section{Fabiana Luci de Oliveira}

Doutora em Ciências Sociais pela Universidade Federal de São Carlos (UfSCar). Professora Adjunta do Centro de EducaÇÃo e Ciências Humanas do Departamento de Sociologia da UfSCar. Pesquisadora do Conselho Nacional de Desenvolvimento Científico e Tecnológico (CNPQ).

fabianalucidufscar.br

\section{Luciana Gross Cunha}

Doutora em Ciência Política pela Faculdade de Filosofia, LETRAS E CIÊnCIAS HumanAS (FFLCH) dA UNIVERSIDADE DE São Paulo (USP). Professora da Escola de Direito de São Paulo da Fundação Getulio Vargas (FGV diREito SP).

Luciana.Cunhalafgv.br 